\title{
Decision Support System of Poor Community Category in Sampang District using AHP (Analytical Hierarchy Process)
}

\author{
Eka Mala Sari Rochman ${ }^{1}$, Syarif Hidayatullah ${ }^{2}$, Muhammad Ali Syakur ${ }^{3}$, Achmad \\ Khozaimi $^{4}$, Achmad Jauhari ${ }^{5}$, Yoga Dwitya Pramudita ${ }^{6}$, Aeri chmad ${ }^{7}$ \\ \{ekamala.sari@yahoo.com ${ }^{1}$, aery_r@yahoo.com ${ }^{7}$ \} \\ Faculty of Engineering, University of Trunojoyo Madura. Raya Telang Road P.O.BOX, Kamal, \\ Bangkalan-Madura, Indonesia ${ }^{1234567}$
}

\begin{abstract}
The Central Bureau of Statistics is a government agency engaged in community data collection, one of which is the data collection of the poor. The government has a program to help the poor, it is just that the aid is often misaligned because of the data's uncertainty. It is closely related to the data collection process that is still conducted manually so often that it experiences data inaccuracies. This study discusses how Decision Support System (DSS) can be utilized by Central Bureau of Statistics to conduct the process of categorizing the poor. The system used is AHP (Analytical Hierarchy Process) method, which is to create a hierarchical arrangement of criteria to solve the complex problems by categorizing the poor by assigning values to each variable with the highest priority. A DSS with AHP method can produce the right decision for Central Bureau of Statistics to channel aid to the poor.
\end{abstract}

Keyword: central bureau of statistics, AHP, DSS, poor.

\section{Introduction}

Nowadays, technological advances are very important. It is in line with the development of computerized systems dominating in various aspects of life, escpecially in working area since technology help people work be more effective and efficient. Information is defined as data processing so that it becomes meaningful for the recipient of the information and useful for current or future decision making. This is true in every activity that runs on government agencies, which is the data collection of the poor, it can happened in Central Bureau of Statistics.

Sampang Central Bureau of Statistics is a non-departmental government agency directly responsible to the President. Previously, BPS was the Central Bureau of Statistics, established under the Act Number 6 of 1960 concerning the Census and Law Number 7 year 1960 on Statistics, one of whose task was to record the number of poor people in indonesia[1]. The data then is used to make the statistics of the poor. The increasing number of poor people makes the government difficult to distribute the aid to the right target. Because of it, mapping of the poor is needed.

Since the manual process of data collection often creates error, a decision support system is needed in order that the decision can be taken objectively. Decision Support System is a computer-based system which can perform data processing more quickly based on the methods

ICCSET 2018, October 25-26, Kudus, Indonesia

Copyright (C) 2018 EAI

DOI 0.4108/eai.24-10-2018.2280560 
implemented[2]. The use of Decision Support System is to assist the decision makers in utilizing certain data and models to solve unstructured problems, namely problems whose solution involves human intuition [3].

One method that can be used is AHP (Analytical Hierarchy Process). This method, using a comparison of several options with predetermined criteria, can help solve problems in customer funding identification that requires many criteria appropriately[4].

This study discusses how AHP can be applied to the decision-making system for categorizing the poor based on criteria Electricity, number of dependents in the family, type of walls and land area of the house, and home ownership. it can be used by the Central Bureau of Statistics to distribute targeted government assistance to the poor.

\section{Methodology}

\subsection{Data Collection}

The data used in this study is from Central Bureau of Statistics-Sampang Regency which was collected in 2017. The criteria of people categorized as the poor defined by Central Bureau of Statistics-Sampang Regency are as follows:

1. The consumption of household electric power becomes the first variable to decide whether someone is categorized as poor people. In Indonesia, the amount of electric power is grouped into 450 watt, 900 watt, 1300 watt, and 2200 watt. The less consumption of household electric power is one of the indicators to consider someone as the poor.

2. The number of family dependents; it is used to measure monthly expenses per life.

3. The type of the house's walls which refers to what material the wall is made of, like concrete, bamboo, wood, or wooden board; it is used to estimate the condition of the house. The people whose house made of traditional material like wood or bamboo is prioritized.

4. The size of the land owned; the smaller land a person have, the more prioritized he is.

5. The Status of the house ownership, where they live in

\subsection{AHP (Analytical Hierarchy Process)}

AHP is one of the decision support models developed by describing complex multi-factor or multi-criteria problems into a hierarchy [5]. This hierarchical decision support model is defined as a representation of a complex problem in a multi-level structure, from the goal as the first level, followed by the factor level, criteria, sub-criteria, to the alternative as the last level. With the hierarchy, a complex problem can be broken down into groups that are then organized into a hierarchical form in such a way that the problem seems to be more structured and systematic. Determining the element's priority arrangement is carried out by arranging pairwise comparison which is comparing in pair all aspects for each sub-hierarchy. The comparison is transformed in matrix form. For example, n objects denoted by (A1, A2, ..., An) are judged based on the importance of the values, such as $\mathrm{Ai}$ and $\mathrm{Aj}$, and then presented in the Pair-wise Comparison matrix. Table 1 shows the pairwise comparison. 
Table 1. Pairwise comparison.

\begin{tabular}{lllll}
\hline & $\mathrm{A}_{1}$ & $\mathrm{~A}_{2}$ & $\ldots \ldots$ & $\mathrm{A}_{\mathrm{n}}$ \\
\hline $\mathrm{A}_{1}$ & $\mathrm{a}_{11}$ & $\mathrm{a}_{12}$ & $\ldots \ldots$ & $\mathrm{a}_{11}$ \\
$\mathrm{~A}_{2}$ & $\mathrm{a}_{21}$ & $\mathrm{a}_{22}$ & $\ldots \ldots$ & $\mathrm{a}_{2 \mathrm{n}}$ \\
$\ldots \ldots$ & $\ldots \ldots$ & $\ldots \ldots$ & $\ldots \ldots$ & $\ldots \ldots$ \\
$\mathrm{A}_{\mathrm{n}}$ & $\mathrm{a} 1$ & $\mathrm{a}_{\mathrm{m} 2}$ & $\ldots \ldots$ & $\mathrm{A}_{\mathrm{mn}}$ \\
\hline
\end{tabular}

The value of $\mathrm{a}_{11}$ is the ratio value of element $\mathrm{A}_{1}$ (row) to $\mathrm{A}_{1}$ (column) states the relationship of one aspect to the other, like:

1. How far the importance of $A_{1}$ (row) to criteria $C$ is

2. How far the dominance of $A_{1}$ (row) to $A_{1}$ (column) is compared to $A_{1}$ (column)

3. How many $\mathrm{C}$ criteria properties on $\mathrm{A}_{1}$ (row) are compared to $\mathrm{A}_{1}$ (column).

The weighting matrix can be seen in the formula (1):

$$
\text { Priority Weight }=\frac{\text { Number of Rows }}{\text { Number of Coloumn }}
$$

It is proven that the Consistency Index of the order matrix can be obtained from formula (2), in which CI, the ratio of consistent deviation, is the result of the difference between the value of $\lambda$ or the maximum eigen value and the value of the elements, devided by the result of the value of the elements minus 1 .

$$
\mathrm{C} 1=\frac{\lambda \text { maks }-\mathrm{n}}{\mathrm{n}-1}
$$

If $\mathrm{CI}$ is zero, then pairwise comparison matrix is consistent. The inconsistency limit established by Thomas L. Saaty was determined by using the Consistency Ratio (CR), i.e. the comparison of the consistency index with the random index value (RI) obtained from an experiment by Ridge National Laboratory, which then was developed by the Wharton School. This value depends on the matrix order n. Thus, the Consistency Ratio can be formulated as follows:

$$
\text { C. } R=\frac{\text { C.I }}{\text { R.I }}
$$

The inconsistency of opinion from the decision maker is still acceptable when the pairwise comparison matrix with CR value is less than 0.100; otherwise, the assessment needs to be repeated. In applying AHP method the following steps should be done [6]:

1. Defining the problem and determining the desired solution.

2. Creating a hierarchical structure that begins with the primary purpose.

3. Creating a pairwise matrix depicting the relative contribution or influence of each element to the above-stated objectives or criteria.

It can define pairwise comparisons, so as to derive the total number of judgments of $\mathrm{n} \times[(\mathrm{n}-$ 1) / 2] pieces, where $n$ is the number of elements that are compared. Table 3 shows the hierarchy comparison scale in criterion [4]. 


\subsection{Flowchart system}

The AHP flowchart depicts the steps of data processing to get the ratio consistency, including determination of the comparison scale, the square of the matrix, normalization of the matrix, and calculation of the ratio consistency. The flowchart is shown in Figure 1.

Table 2. Quantitative Scale in decision support systems.

\begin{tabular}{cl}
\hline $\begin{array}{c}\text { The Intensity of } \\
\text { Interest }\end{array}$ & \multicolumn{1}{c}{ Interests } \\
\hline 1 & Both Elements Equally Important \\
3 & One Element Slightly More Important of Other Elements \\
5 & The One Element Is More Important of Other Elements \\
7 & One Element is More Absolute Important of Other Elements \\
9 & One Absolute Element Matters From Other Elements \\
$2,4,6,8$ & Values Between Two Value Related Considerations \\
The opposite & If Activity I Gets One Number Compared To A Activity, Then A \\
\hline
\end{tabular}

\section{Output Analysis}

The first step of the analysis is determining which the most important criteria is, which is called pair-wire comparison in AHP terminology. Table 4 shows the matrix of pair comparison. Which sum is the sum of all the numbers on the line above in one column, Number 3 is derived from the number of criteria, i.e. price, features and technology. Priority Vector shows the weight of each criterion, so in this case the price is the most important weight in the selection of the poor. To check whether the weights are made consistent or not. So the thing to do is calculate the Principal Eigen Value (lmax) matrix.

Table 3. Pair comparison matrix.

\begin{tabular}{|c|c|c|c|c|c|c|}
\hline \multirow[b]{2}{*}{ Criteria } & \multicolumn{6}{|c|}{ Pair comparation matrix } \\
\hline & $\begin{array}{l}\text { Electrical } \\
\text { power }\end{array}$ & tmortgage & $\begin{array}{l}\text { Wall } \\
\text { Types }\end{array}$ & assets & work & $\begin{array}{l}\text { Priority } \\
\text { Vector }\end{array}$ \\
\hline $\begin{array}{l}\text { Electrical } \\
\text { power }\end{array}$ & 1 & 3 & 5 & 3 & 5 & 0,4450 \\
\hline dependents & 0,33 & 1 & 3 & 3 & 3 & 0,2324 \\
\hline Wall type & 0,2 & 0,33 & 1 & 3 & 3 & 0,1514 \\
\hline Land area & 0,33 & 0,33 & 0,33 & 1 & 3 & 0,1118 \\
\hline $\begin{array}{l}\text { Status of } \\
\text { building } \\
\text { ownership }\end{array}$ & 0,2 & 0,33 & 0,33 & 0,33 & 1 & 0,0594 \\
\hline amount & 2,07 & 5,00 & 9,67 & 10,33 & 15,00 & 1,0 \\
\hline \multicolumn{3}{|c|}{ Pricipal Eigen Value (lmax) } & & & & 6,0 \\
\hline \multicolumn{3}{|c|}{ Consistency Index (CI) } & & & & 0 \\
\hline \multicolumn{3}{|c|}{ Consistency Ratio (CR) } & & & & $0,0 \%$ \\
\hline
\end{tabular}




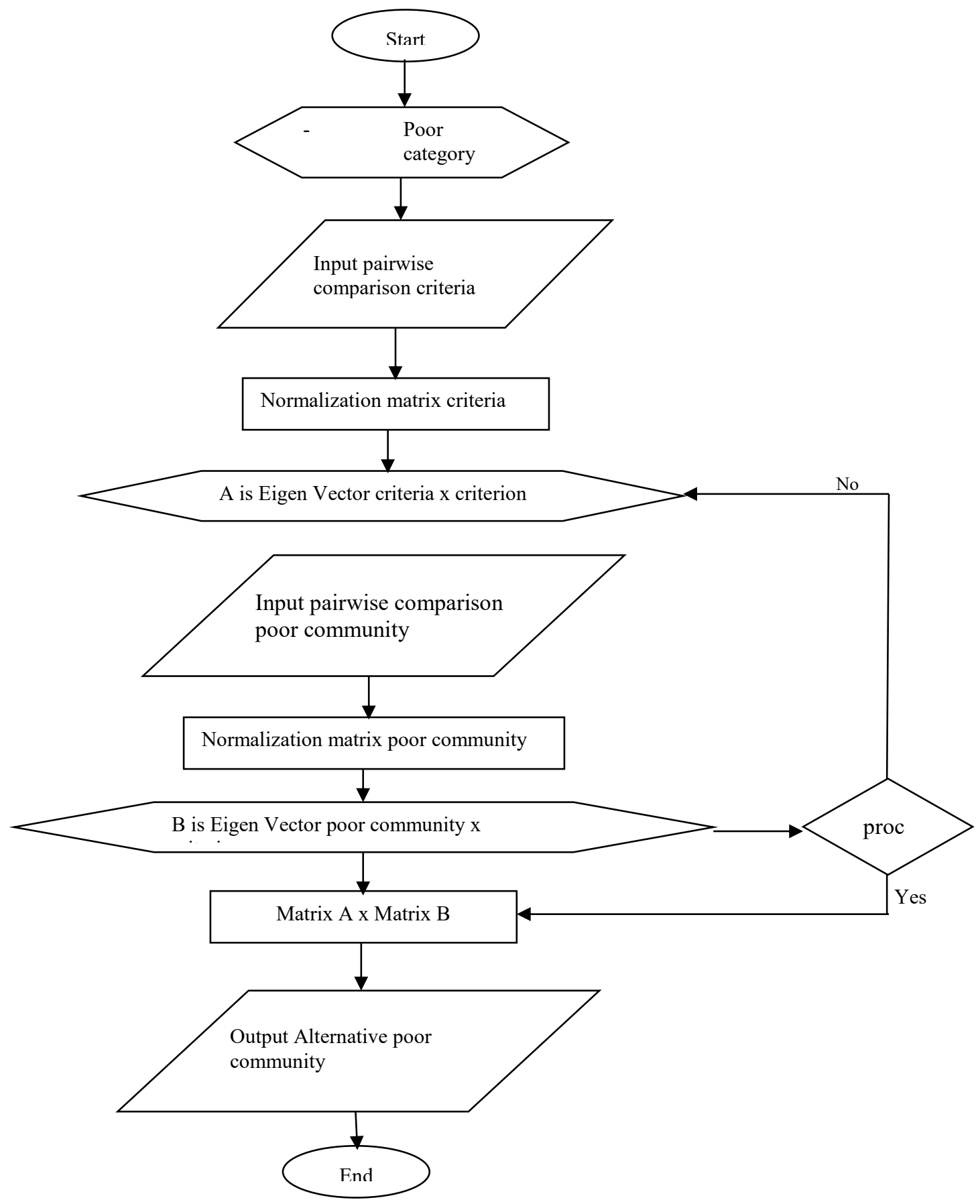

Fig 1. AHP flowchart system. 
The second step is assesing the community based on the evaluation of the weight of electric power, of the weight of dependents, of the weight of the type of wall, of the weight of land area and of the weight of the work. The next step is getting the weight for the three criteria, and the last step is to calculate the total score. All the assessment results are in the form of a table called Overall composite weight Columns (Syamsul, Haris, Hadori) taken from the priority vector column of the three matrix such as Electrical power, Dependent, Types of Wall, Land Area, Ownership status and Composite Weight. The weight is taken from the Priority Vector column in the criteria matrix. Table 5 shows the overall composite weight.

Table 4. Overall composite weight.

\begin{tabular}{lcccc}
\hline $\begin{array}{c}\text { Overall composite } \\
\text { weight }\end{array}$ & Weight & Syamsul & Haris & Hadori \\
\hline Electrical power & 0,4450 & 0,6232 & 0,3333 & 0,2332 \\
Dependence & 0,2324 & 0,3645 & 0,3333 & 0,3332 \\
Type of wall & 0,1514 & 0,3332 & 0,9998 & 0,3332 \\
Land area & 0,1118 & 0,3323 & 0,3698 & 0,2979 \\
Ownership status & 0,0594 & 0,3603 & 0,5123 & 0,1274 \\
Composite Weight & & 0,4710 & 0,9698 & 0,6973 \\
\hline
\end{tabular}

From the table above it can be seen that Haris has the highest score of 0.9698 , then followed by Hadori with 0.6973 and in the bottom rank is Syamsul with 0.4710 . From this result it can be said that Haris is the poorest of all.

The analysis is a way to solve problems based on data that have been obtained from the results of field studies. To improve the quality of the data collection category of the poor. In Sampang district have made application of decision support system category of the poor to be more effective. This application serves to facilitate the selection of types of poor people which includes sick or not. It can display like a log out, and have some form such as login form, public data form; Criteria form data, form criteria value, form value of society. The login form and main page are shown in Figures 7 and 8. Figure 9 is a form for beneficiaries and figure 10 is a form of community data. Both of these form admin can process such as input, edit and delete

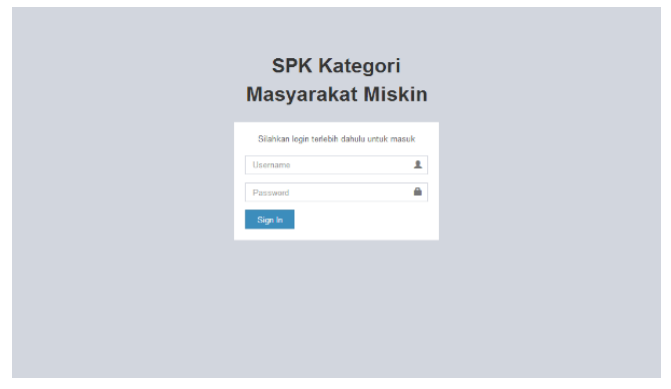

Fig. 7. Login form.

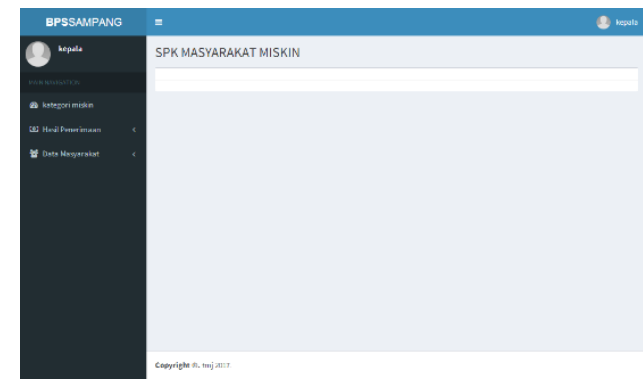

Fig. 8. Main page. 


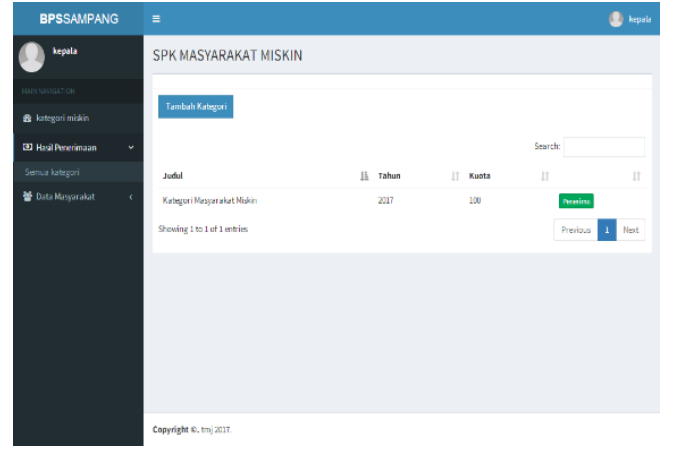

Fig.9. Input of receiver data.

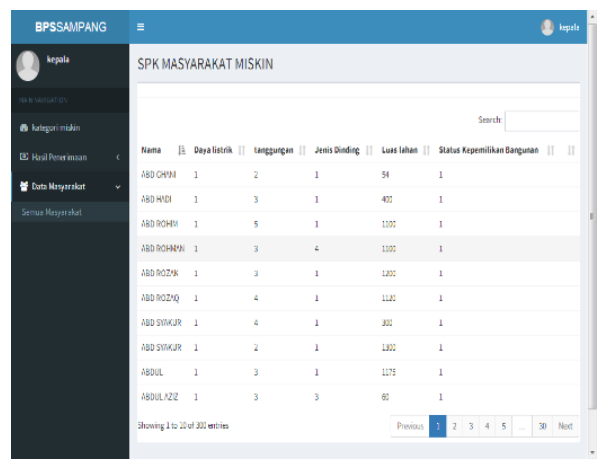

Fig. 10. Community Data.

Figures 12 and 13 show a form categories and fill forms to enter categories. Both of these forms aim to update the number of categories desired by BPS by applicable rules. That process making it easy to add new categories or delete old categories.

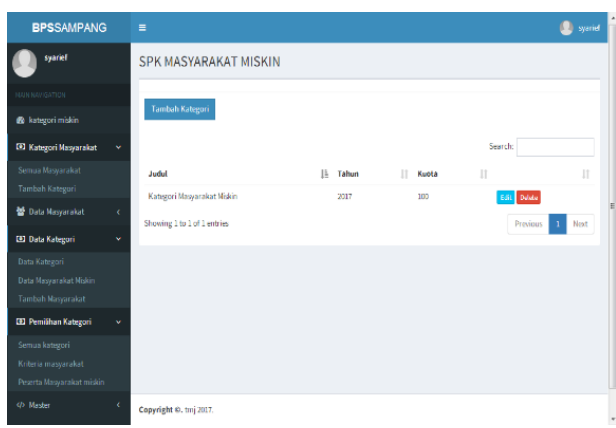

Fig.12 Form category.

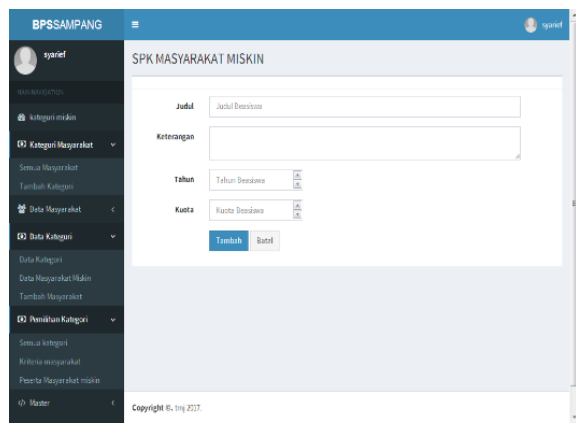

Fig. 13. Menu form added category.

Matrix form criteria can calculate the category matrix as supporting the method AHP, which is shown Figure 14. Figure 15 shows the form parameters that is to add and set subcriteria of the criteria.

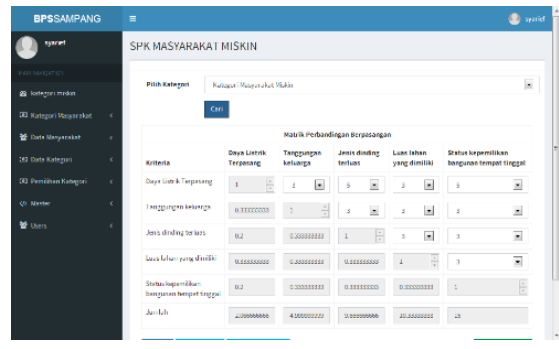

Fig. 14. Calculating the Matrix.

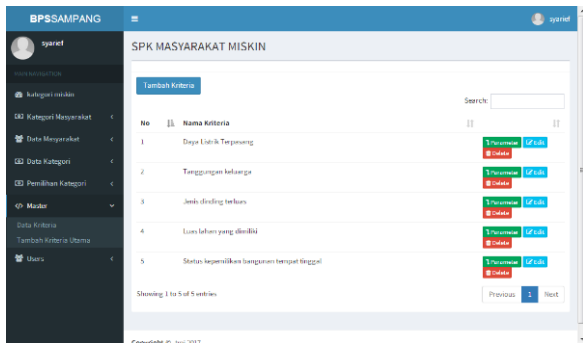

Fig. 15. Parameter criteria. 


\section{Conclusion}

1. It is proven that with appropriate data criteria the decision support system program can help Central Bereau of Statistics administrator conduct the selection of poor people precisely and quickly

2. Applying AHP to the decision support system program to identify the poor is proven to be effective and give precise result.

3. Priority Vector value of the criterion weight can be determined as the highest weight in the selection of the poor and Principal Eigen Value can be calculated the value of consistent weight

\section{References}

[1] "Central Bereau of Statistics, “"jdih.bps.go.id, [Online]. Available: jdih.bps.go.id/files/produk_hukum/uu/P0219606.pdf." .

[2] B.W.W.K.a.S.F. Kanyarat Phudphad, "Rankings of the security factors of human resources information system (HRIS) influencing the open climate of work: using analytic hierarchy process (AHP)," Procedia Comput. Sci., vol. 111, pp. 287-293, 2017.

[3] F.F.e.a, "Decision Support System," Springer Int. Publ., p. 31, 2017.

[4] O.B.S.G.R. Radu Eugen Breaz, "Selecting between CNC milling, robot milling and DMLS processes using a combined AHP and fuzzy approach," Procedia Comput. Sci., vol. 122, pp. 796-803, 2017.

[5] G.B.I.G.G.S.N.F.G.I. Ioan Aschilean, "Choosing the optimal technology to rehabilitate the pipes in water distribution systems using the AHP method," Energy Procedi, vol. 112, pp. 19-26, 2017.

[6] T.L. Saaty, "Decision Making for Leaders of the AHP Series," Int. J. Serv. Sci., vol. 1, pp. 8398, 2008. 